\title{
ICMAT 2005-IUMRS-ICAM 2005 Covered Frontiers of Materials Science, Engineering, and Technology www.mrs.org.sg/icmat2005
}

The 3rd International Conference on Materials for Advanced Technologies (ICMAT 2005), combined with the International Union of Materials Research Societies 9th International Conference on Advanced Materials (IUMRS-ICAM 2005), was held July 3-8, 2005, in Singapore. The conference was organized by MRSSingapore in association with the National University of Singapore (NUS), the Institute of Materials Research and Engineering (IMRE), and Nanyang Technological University (NTU). NUS furthermore celebrated its centennial year at this conference.

The conference hosted plenary lectures delivered by Nobel Laureates Steven Chu (Lawrence Berkeley National Laboratory, USA) on "Miniaturization in Biology," Carl E. Wieman (Univ. of Colorado, USA) on "Dilute Gas BEC: A Very Novel Quantum Material," and Roald Hoffmann (Cornell Univ., USA) on "Waiting to be Made." In honor of the centennial celebration of NUS, the Nobel Laureates also presented lectures for conference participants and the general public, including students from universities, junior colleges, and polytechnic institutes (see sidebar on page 880 ).

In addition, the conference featured five additional plenary lectures and four theme lectures (see sidebar) as well as 25 technical symposia, a banquet, and a three-day exhibition by 50 vendors and equipment manufacturers. The conference saw 2250 delegates from 56 countries, who presented more than 2000 papers. Singapore, Japan, China, India, Korea, and the United States had the largest contingents. More than 800 posters were presented during three days of the conference. One poster from each symposium was selected for a Best Poster award. Among the theme lectures was an award presentation delivered by Zenji Horita (Kyushu Univ., Fukuoka, Japan), who received the IUMRS Sōmiya Award with Terence G. Langdon (Univ. of Southern California, Los Angeles, USA) for their collaboration on severe plastic deformation as a means of processing materials. Following are highlights of the research presented in the technical symposia.

D.F. Williams (editor in chief, Biomaterials) opened Symposium A on "Advanced Biomaterials" with the keynote address on the issue of biocompatibility of biomaterials; A. Hoffman (Univ. of Washington, USA), known as the "grandfather of polymeric biomaterials," spoke

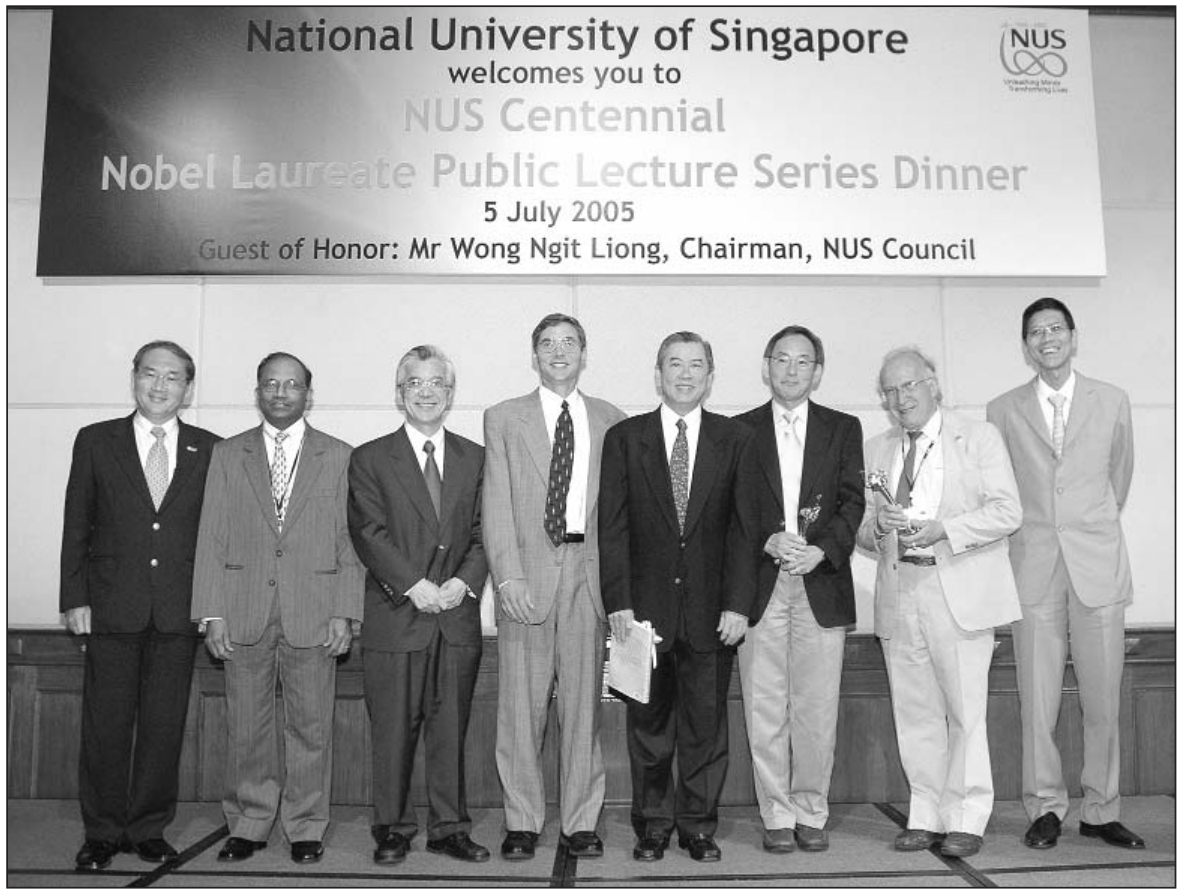

(From left to right): Liew Ah Choy (director, International Relations Office, National University of Singapore), B.V.R. Chowdari (organizing chair and president of MRS-Singapore), Shih Choon Fong (president, NUS), Carl Wieman (Nobel Laureate in physics, University of Colorado, USA), Wong Ngit Liong (chair, NUS Council), Steven Chu (Nobel Laureate in physics, Lawrence Berkeley National Laboratory, USA), Roald Hoffmann (Nobel Laureate in chemistry, Cornell University, USA), and Tan Chorh Chuan (provost, NUS)

on new smart polymers for microfluidic devices that could selectively conjugate proteins by simply changing the temperature; and T. Okano (Tokyo Women's Medical Univ., Japan), known as the "champion" of cell sheet technology, gave an outstanding theme lecture and inspired the audience with reports of the many clinical successes, especially in corneal tissue engineering. A. Mikos (coeditor, Tissue Engineering) gave further insights into new trends in scaffolds for tissue engineering; and K.W. Leong (Johns Hopkins Univ. School of Medicine, USA) described the vast opportunities in nanofiber technology. Y. Tabata (Kyoto Univ., Japan) addressed growth factors and drug-delivery systems; S. Best (Univ. of Cambridge, UK) addressed bioceramics; and T.C. Lim (NUS, Singapore) described the clinical success of a scaffold platform technology for cranium bone regeneration that has benefited more than 20 patients. The symposium also featured presentations on surface modifications and nanobiotechnology.
In Symposium B, interfacial interactions at the molecular and nanometer scale were discussed. In the area of surface science, S.F. Bent (Stanford Univ., USA), F. Rochet (Univ. Pierre et Marie Curie, France), and J. Yoshinobu (Univ. of Tokyo, Japan) presented their recent studies on interfacial interactions between organic molecules and semiconductor substrates. X. Peng (Univ. of Arkansas, USA) discussed the vital role of ligand monolayer on the surfaces of nanocrystals where interface chemistry meets nanoscience; X.Y. Zhu (Univ. of Minnesota, USA) described recent efforts in the understanding of molecule-metal interfaces in assembly structures; and J. Hrbek (Brookhaven National Laboratory, USA) discussed the manipulation of nanoparticle growth on surfaces. In the area of bionanotechnology, biologically functionalized surfaces were introduced, ranging from the immobilizing technique of protein microarrays to recent developments in surface biochemistry for genomics, proteomics, and personalized medicine. 
Symposium C on "Biomedical Devices and Instrumentations" covered frontier areas of materials research, device design, and processing technologies for biomedical applications. It brought together medical device designers, manufacturers, researchers, and representatives from the practicing medical community under one banner to discuss current and future technology needs to promote the biomedical industry around the globe. Most of the scientific presentations stressed the importance of simple, cost-effective, portable/disposable, and reliable microdevices and targeted immediate applications in the life sciences. The journal Biomedical Microdevices: BioMEMS and Biomedical Nanotechnology has agreed to publish the papers from this symposium.

Symposium D covered various aspects of magnetic materials and devices. Recent progress in the field of dilute magnetic materials, such as current-induced domain wall switching, were reported. Magnetic characterization techniques at the nanometer scale, ranging from scanning probe microscopy to atomic probe and transmission electron microscopy, were discussed. The talks on novel magnetic materials focused on magnetism of carbon and extremely soft magnetic alloys.

Frontier topics of research in various aspects of mechanical behavior of nanoand microscale systems and advanced materials were explored in Symposium E. Presentations covered issues related to advanced materials such as single-crystal silicon, metallic alloys, carbon nanotubes, polymeric composites, thin films or multilayers, microelectronic materials such as lead-free solder materials, metallic glass, micro- and nanoelectromechanical systems, and bio- and nanostructured materials. In mechanical aspects, the topics of contact mechanics, finite element simulation, molecular dynamics simulation, fracture and deformation, fatigue, viscoelasticity, and the strength of nanostructured materials were addressed. Recent developments and applications of instrumented indentation to various industrial areas were also discussed. Applications of carbon nanotubes were also presented. Papers will be published as a special issue of Materials Science and Engineering A.

Symposium F on "Nano-Optics and Microsystems" covered a large and diverse field of key technologies from advanced microelectromechanical system (MEMS) technologies, nanophotonicbandgap integrated circuits, and biophotonic medical devices to bio-MEMS. Highlights of the invited talks included molecular/cellular bionanotechnology for future molecular medicine, multifunc- tional microsystems in plastics, very high-aspect-ratio micro- and nanostructures, and lab-on-a-chip microfluidic systems for DNA/RNA extraction. Notably, invited talks on the challenges facing MEMS commercialization and rf MEMS without moving parts were well-received by the participants and provoked much discussion, since the marketability of MEMS products is one of the ultimate aims and rf MEMS without moving parts were unthinkable years ago. The symposium also drew a huge following of participants in technical sessions that hosted advanced topics such as microfluidic chips for protein arrays and malaria diagnosis, scanning probe microscopy probes using NEMS (nanoelectromechanical systems) technology and high-aspect-ratio through-wafer copper vertical interconnects for MEMS packaging. Selected papers of this symposium will be published in a special journal issue of Sensors and Actuators A: Physical.

Presentations in Symposium G on "Nanodevices and Nanofabrication" included electronic devices on the nanoand molecular scales, nanomechanics and NEMS, synthesis and characterization of nanostructures, fabrication technologies for nanodevices and nanostructures, manipulation and aligning processes at nanometer/molecular scales, quantum phenomena, and modeling of nanodevices and nanostructures. Papers presented at the symposium will be published as a special issue of the International Journal of Nanoscience.

The theme of Symposium H on "Si Microelectronics: Processing to Packaging" reflected major areas of research in the fields of microelectronics ranging from nanodevices to nanosystems packaging. D.L. Kwong (Inst. of Microelectronics, Singapore) gave the keynote address, followed by presentations on nanodevices and complementary metal oxide semiconductor processes, $\mathrm{Cu}$ interconnect materials and processes, and advanced packaging technologies that would play a crucial role in the realization of the requirements set forth by the International Technology Roadmap for Semiconductors (ITRS).

The nanodevices and materials fields witnessed excellent presentations in the areas of materials for sub-90-nm node devices, $\mathrm{Si} / \mathrm{SiGe}$ on insulator technologies, strained $\mathrm{Si}$, high-dielectric-constant materials and processes as well as novel nanoscale devices. Presentations on $\mathrm{Cu}$ interconnect technologies focused on $\mathrm{Cu}$ plating processes, low- $\kappa$ dielectric materials and integration, barrier materials, adhesion properties, surface cleaning methodologies, electromigration, dielec- tric breakdown, and related reliability considerations. The packaging sessions covered topics ranging from wafer-level packaging, $\mathrm{Cu}$ wire bonding, Au wire bonding and reliability phenomena, and electromigration in solder joints, to fatigue, creep, mechanical shock and vibration phenomena in solder joints, and relevant aspects of optoelectronics packaging. Selected papers presented at this symposium will be published as a special issue of Thin Solid Films.

A highlight of Symposium K on current research and development efforts in $\mathrm{SiC}$ and related materials was the report of a bulk crystal growth technique involving repeated $a$-face growth followed by $c$-face growth to produce wafers with a dislocation density of $<75 \mathrm{~cm}^{-2}$. This suggests that the prospect for obtaining dislocationfree $4 \mathrm{H}-\mathrm{SiC}$ wafers may not be too far in the future. Other highlights included presentations on a high-temperature chemical vapor deposition (CVD) technique that could produce $2-3$ in. epitaxial $4 \mathrm{H}-\mathrm{SiC}$ wafers with micropipe densities of $<0.5 \mathrm{~cm}^{-2}$ and the production of freestanding 3C-SiC wafers grown on undulant $\mathrm{Si}$ wafers designed to reduce stacking faults and eliminate antiphase boundaries. The symposium also saw an informative discussion of defect levels at both oxide-SiC interfaces and in bulk $\mathrm{SiC}$ to explain the electronic properties of $\mathrm{SiO}_{2}-$ $\mathrm{SiC}$ structure, semi-insulating and degenerately doped $4 \mathrm{H}-\mathrm{SiC}$.

Symposium M on "Photonic Materials and Devices" covered a broad range of materials including III-V and dilute nitride semiconductors, quantum dots and nanocrystals, oxides and silicon, polymers, and organics. J.H. Marsh (Intense Photonics, UK) spoke on the use of quantum-well intermixing (QWI) for passivating the facets required to improve the reliability of high-power laser diode arrays. One application is in digital printing. O. Acher (CEA Le Ripault, France) described significant advances in laser cutting of paper for desktop applications, using a $1 \mathrm{~W}$ laser diode and a specially formulated ink that absorbs in the near-infrared. QWI has also been extended to modify selectively the properties of quantum dot (QD) materials. C. Jagadish (Australian National University) discussed advances in growing QDs on pre-patterned substrates for integrated optoelectronics. M. Hopkinson (Sheffield Univ., UK) discussed the use of a unique molecular-beam epitaxy technique to grow dot-in-well (DWELL) structure to realize InAs/InGaAs quantum dot lasers at 1310 $\mathrm{nm}$ with a low threshold current density of $17 \mathrm{~A} / \mathrm{cm}^{-2}$ and an output power as high as $100 \mathrm{~mW}$. 
C. Tu (University of Calif., San Diego) presented a detailed material study of dilute nitride III-V compound semiconductors, which have garnered much recent interest because a small amount of nitrogen can result in a large change in bandgap and band structure. In particular, incorporating $0.5 \%$ nitrogen in $\mathrm{GaP}$ results in a change in the band structure from indirect to direct, making it possible to fabricate a red LED on a transparent GaP substrate. On the other hand, GaInNP grown on $\mathrm{GaAs}$ has a very small conduction band offset; thus, GaInNP doped with Si could be an ideal emitter and collector material for GaAs-based $n-p-n$ heterojunction bipolar transistors (HBTs).

Epitaxy of III-V photonics on silicon can be used to create a platform capable not only of higher electron and hole mobilities in one material, but also of integrating optical devices to increase functionality and improve material performance. This heterogeneous integration was the subject discussed by E. Fitzgerald (Massachusetts Institute of Technology, USA) and S. Ringel (Ohio State Univ., USA). Fitzgerald presented the materials challenges and innovations achieved to bring III-V materials and Si together on a common substrate to achieve a Si-chip that can support electrical and optical interconnects. Ringel discussed the growth of GaAs on Si using step-graded SiGe interlayers to accommodate the $4 \%$ mismatch in lattice constants between $\mathrm{GaAs}$ and Si. Advances in photovoltaics are also enabled by the introduction of metamorphic multijunction solar cells. Ringel's group also announced its roomtemperature electrically pumped red laser diodes grown on $\mathrm{Si}$.

The field of organic electronics and lightemitting diodes (LEDs) also received significant attention. Th. Birendra Singh and colleagues at Johannes Kepler University in Austria reported on the interfacial effects of trapped charges at the polymeric dielectric-organic semiconductor interface in organic field-effect transistors (OFETs). They demonstrated a fullerene-based $n$ channel OFET exhibiting an electron mobility of $2.5 \mathrm{~cm}^{2} / \mathrm{Vs}$ with an on/off ratio in excess of $10^{5}$, as well as a photoactive OFET using a donor-acceptor blend, that is, conjugated polymer/fullerene solid-state mixtures, showing a very high ratio of photocurrent to dark current.

In Symposium $\mathrm{N}$ on " $\mathrm{ZnO}$ and Related Materials," M. Kawasaki (Tohoku Univ., Japan) gave an invited talk on $p$-type doping and LEDs based on $\mathrm{ZnO}$. His group announced its $\mathrm{ZnO}$ homojunction LED with ultraviolet emission using a repeated temperature modulation technique. This

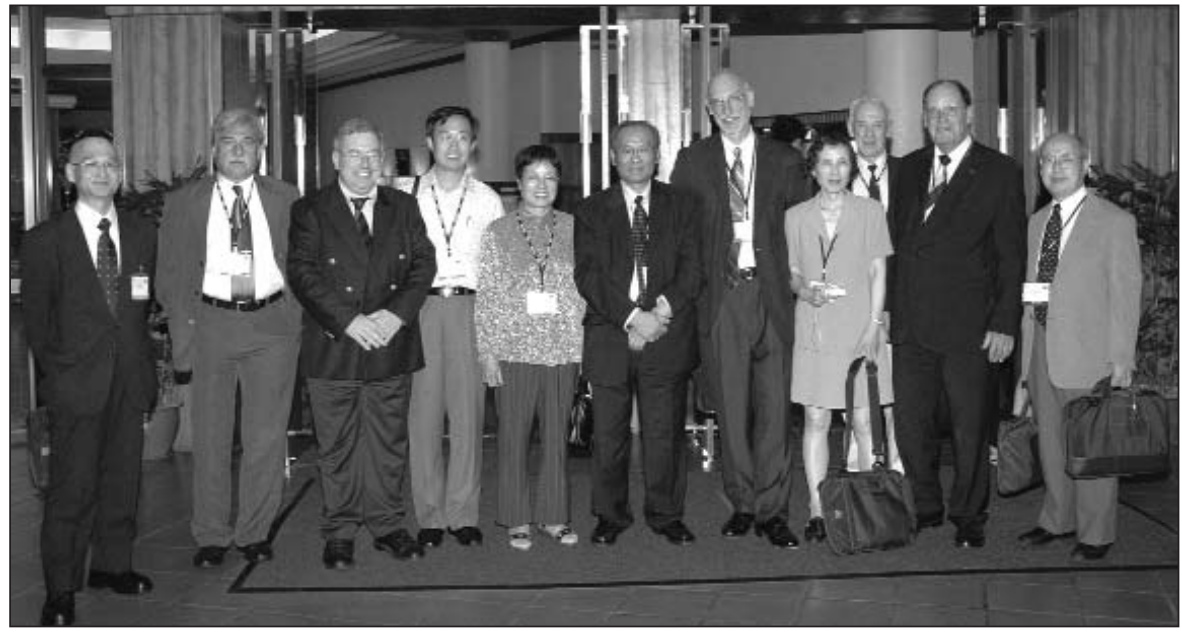

(From left to right): Representatives of some of the adhering bodies of the International Union of Materials Research Societies: Hiroshi Yamamoto (MRS-Japan), H.-U. Habermeier (European-MRS), Gabriel M. Crean (European-MRS/IUMRS), Guoqing Zhang (ChineseMRS/IUMRS), Mrs. Zhou Lian, Zhou Lian (Chinese-MRS/IUMRS), Robert J. Nemanich (MRS/IUMRS), Ya-Fang Han (Chinese-MRS), John E. Baglin (MRS/IUMRS), Peter A. Glasow (European-MRS/IUMRS), and Masahiro Yoshimura (MRS-Japan)

novel technique may lead to $\mathrm{ZnO}$-based UV lasers in the near future. Ferromagnetism in transition-metal-doped $\mathrm{ZnO}$ remained controversial. K.V. Rao (Royal Inst. of Technology, Sweden) reported a novel $\mathrm{Cu}$-doped $\mathrm{ZnO}$ system that exhibited ferromagnetism with a Curie temperature $\left(T_{\mathrm{C}}\right)$ above $450^{\circ} \mathrm{C}$. Such a phenomenon observed in $\mathrm{ZnO}: \mathrm{Cu}$, which contains no magnetic transition elements, is unusual. The proceedings of the symposium will be published as a special issue of the Journal of Crystal Growth.

The importance of alternative energy sources and the so-called hydrogen economy was evident in Symposium P on "Materials for Rechargeable Batteries, Hydrogen Storage and Fuel Cells" as the level of participation necessitated parallel sessions, PA and PB. Lithium-ion batteries (LIBs) received great emphasis in Session PA. Recent developments in understanding the behavior of second-generation, positive electrode (cathode) materials such as $\mathrm{Li}\left(\mathrm{Ni}_{x} \mathrm{Mn}_{x} \mathrm{Co}_{1-2 x}\right) \mathrm{O}_{2}(0<x \leq 0.5)$, modified $\mathrm{LiMn}_{2} \mathrm{O}_{4}$, and $\mathrm{LiFePO}_{4}$ were discussed. Aspects of negative electrode materials including graphite, thin-film silicon, metal nitrides, phosphides, antimonides, and silicides were presented. In addition to recent advances in liquid electrolytes for use in LIBs, considerable attention was given to the Li-ion solid electrolytes based on crystalline, amorphous, and glass ceramics. The highlights were the description of fabrication and perfor- mance testing of all-solid bulk and microLIBs for a variety of applications including smart cards.

Session PB focused on hydrogen-energyrelated technologies, with emphasis given to hydrogen storage and fuel cells. The technical challenges in the utilization of hydrogen-based energy, especially in terms of the development of novel solidstate hydrogen storage materials and higher-operating-temperature protonexchange-membrane fuel cells (PEMFCs) were addressed.

Meta-materials or left-handed materials-which are composite structures made of metallic inclusions properly arranged in space in order to achieve negative values of permeability and permittivity-featured strongly as a hot topic of research interest in Symposium $\mathrm{R}$ on "Electromagnetic Materials," since this class of materials exhibits novel and unusual electromagnetic properties that could serve in a range of possible future applications. Other topics that generated great interest among participants were microwave magnetic materials, electronically tunable dielectric materials, and the up and coming area of nanocomposites.

In Symposium S on "Science and Technology of Hybrid Materials," T. Tsakalakos (Rutgers Univ., USA) delivered an invited talk on multifunctional hybrid materials for biomedical applications, illustrating the promising potential and challenges of this field. 
F.F. Lange (University of Calif., Santa Barbara) gave an invited talk on poly (dimethylsiloxane) channel stamping/patterning films and ceramics. L. Ren (Xiamen Univ., China) discussed bioactive gelatin-siloxane hybrids as a tissue engineering scaffold for osteoblast growth and differentiated function. Researchers also discussed the current state of the art of hybrid materials. The proceedings of Symposium $S$ will be published in Solid State Phenomena.

Presentations in Symposium T on "Novel Porous Materials for Emerging Applications" emphasized the cutting edge of the science and technology of fabricating novel organic, inorganic, and organic-inorganic hybrid porous materials with hierarchical nanoporous architectures, tailoring pore sizes and surface functionalities for matching the requirements of emerging applications. Discussions focused on new designsynthesis strategies for making functional porous materials with prescribed structural, chemical, and morphological properties for applications in energy storage (e.g., hydrogen storage, supercapacitors, fuel cells, and rechargeable batteries), bioengineering (e.g., drug delivery, immobilization of biocatalysts, and tissue engineering), photonics and electronics, and nanotechnology. Porous materials of various compositions such as silicate, organosilica, silicon, alumina, metal, metal oxide, carbon, polymer, and metalorganic frameworks (MOF) as powders, monoliths, thin films, membranes, and nanoparticles were covered. The papers presented in the symposium will be published in a special issue of the Journal of Materials Chemistry and the Journal of Porous Materials.

Symposium U was the "13th Annual POLYCHAR World Forum on Advanced Materials" (see Web site www.unt.edu/ POLYCHAR). In his invited talk, R. Hoffmann (Cornell Univ., USA) discussed the compartmentalization of materials science. Among other materials, he and his team work on carbides. $\mathrm{He}$ mentioned that many ceramists work on traditional ceramics, cements, and concretes, and most of them avoid carbides since the latter form chains and networks. Polymer scientists-who have the tools to deal with chains and networks-also stay away from studying carbides, believing these are inorganic non-polymeric materials. Many relevant topics on advanced materials were also discussed.

The POLYCHAR-13 Prize Committee awarded, among others, the following prizes: the Paul J. Flory Polymer Research

\section{ICMAT 2005-IUMRS-ICAM 2005 Special Lectures}

Plenary Lectures

- Subra Suresh (Massachusetts Institute of Technology, USA) on "Materials Science Approaches for Cell Biology and Human Disease State"

- C.N.R. Rao (Jawaharlal Nehru Centre for Advanced Scientific Research, India) on "Chemical Routes to Nanomaterials"

- Bernard Raveau (ENSICAEN, France) on "The Future of Oxides as Functional Materials"

- Masuo Aizawa (Tokyo Inst. of Technology, Japan) on "Bio-Nanotechnology/NanoBiotechnology Challenges for Intelligent Materials and Systems"

- Chenming Calvin Hu (Univ. of Calif., Berkeley, USA) on "The Roles of New Materials in Future CMOS Technology"

Theme Lectures

- Paul C.W. Chu (Hong Kong Univ. of Sci. \& Technology, China) on "What Does Nanotechnology have Any Thing to Do with High-Temperature Superconductivity Science and Technology?"

- Denis Fichou (CEA-Saclay, France) on "Building-Up Supramolecular SelfAssemblies on Surfaces: Towards Molecular Nanoelectronics"

- Teruo Okano (Tokyo Women's Medical Univ., Japan) on “Cell Sheet Technology_-A New Revolutionary Tool for Tissue Engineering"

- Zenji Horita (Kyushu Univ., Fukuoka, Japan), IUMRS Sōmiya Award lecture

\section{Nobel Laureate Public Lectures}

(National University of Singapore Cultural Center)

- Steven Chu (Lawrence Berkeley National Laboratory, USA) on "Molecular Biology and Nanotechnology"

- Carl E. Wieman (Univ. of Colorado, USA) on "Bose-Einstein Condensation: Quantum Weirdness at the Lowest Temperature in the Universe"

- Roald Hoffmann (Cornell Univ., USA) on "Chemistry's Essential Tension: The Same and Not The Same"
Award (ex aequo) to Jung-Il Jin, Univ. of Korea, Seoul, and R.P. Singh, Univ. of Lucknow, India; the Carl Klason Award for a Young Investigator to Dhanjay Jhurry, Univ. of Mauritius; and the Bruce Hartmann Award for the Best Student Paper to Ayping Yang, Univ. of Tokyo, Japan, and Shandong Univ., China, for two papers, a poster and an oral presentation.

Recent developments in the preparation, processing, characterization, and applications of polymer nanostructured materials were highlighted in Symposium V. Invited lectures were given by R. Vaia (U.S. Air Force Mater. Res. Lab.) on polymer carbon nanotube composites, W. Knoll (Max Planck Inst. for Polymer Research, Germany) on functional nanoscopic hybrid architectures, J. Vancso (Univ. of Twente, the Netherlands) on chemistry and template fabrication on the nanoscale, D.G.. Kurth (Max Planck Inst. for Colloids and Interfaces, Germany) on functional materials based on metallosupramolecular modules, D.H. Kim (Max Planck Inst. for Colloids and Interfaces, Germany) on nanostructured materials templated by thin films of block copolymers, and W. Jingshen (Hong Kong Univ. of Science and Technology, China) on polypropylene $/ \mathrm{CaCO}_{3}$ nanocomposites. Selected papers will be published in the Journal of Nanoscience and Nanotechnology.

Symposium W on "Advanced Materials and Polymers for Defense and Aerospace Applications" attracted the participation of delegates from institutions across the globe-ranging from the armed forces and defense research laboratories in the United States and contractors in Europe to representatives from institutions in India, China, and Singapore. Sponsored by the U.S. Office of Naval Research (ONR) and the Asian Office of Aerospace Research and Development (AOARD-Tokyo), the symposium was filled with excellent keynote and invited lectures on the state of the art in materials research over a wide spectrum of areas. A common theme in many of the presentations was the realization that composite and hybrid systems-at scales ranging from macro to nano-would be the way of the future, providing advantages over many currently used technologies. The pervasiveness of nanotechnology was evident from the number of speakers who specialized in this area. Overall, the presentations sparked animated discussions among members of the audience. The keynote speakers presented synopses of the materials of the future in the context of evolving and future defense/security requirements. B. Rath (Naval Res. Lab., USA) spoke on defense materials for the 
future; S. Sivaram (Natl. Chem. Lab., India) highlighted the importance of organic-inorganic hybrids; and H. Carlson and $\mathrm{C}$. Lee, both from the Air Force Office of Scientific Research, USA, presented overviews of the research programs and research on polymeric materials, respectively, at their institution.

Symposium X, the "Third Vacuum \& Surface Science Conference of Asia and Australia, VASSCAA-3," was organized to create a forum in Asia and Australia to discuss vacuum, surface, and related sciences, techniques, and applications. The conference was endorsed by the International Union for Vacuum Science, Technique, and Application (IUVSTA). The keynote and invited talks highlighted the latest results in surface, interface, and nanoscale science. E.W. Plummer (Univ. of Tennessee, USA) presented the novel surface phases of correlated electron materials, and K.H. Ploog (Paul Drude Inst., Germany) showed the latest results of in situ studies of epitaxial growth by synchrotron $x$-ray diffraction. S. Rusponi (EPFL, Switzerland) talked about magnetism at the nanoscale, and Z.Q. Qiu (University of Calif., Berkeley, USA) explained the quantum size effect in ultrathin films grown on ferromagnetic substrates. E.G. Wang (Chinese Acad. of Sci., China) addressed adatom diffusion in nanoscale growth, and S.G. Louie (Univ. of Calif., Berkeley and Lawrence Berkeley Natl. Lab., USA) discussed the theory and computation of optical, transport, and mechanical properties of nanostructures.

Symposium Y on "Optical Spectroscopic Techniques" covered a wide range of frontier scientific research and advanced tech- nologies that utilize spectroscopic characterizations. The electronic properties of semiconductor quantum structures were reviewed. These two-, one-, and zerodimensional structures are vitally important to optoelectronic, photonic, and biological applications. The use of optical spectroscopic methods as noninvasive diagnostic techniques were presented as well as probing molecular structures using femtosecond time-resolved spectroscopy. Near-field scanning optical microscopy that combines chemical-specific information with nanometer spatial resolution, surface-enhanced Raman spectroscopy using noble and rare-earth metal nanoparticles that allows single-molecule detection, and the latest developments in optical instrumentation were among the topics discussed. The presented papers will be published in a special on-line conference issue of the Journal of Physics: Condensed Matter.

Symposium Z on "Education in Materials Science, Engineering and Technology" featured dynamic and innovative programs in materials education at all levels and included in-depth discussions of the many challenges in sustaining effective programs to meet the fast-changing needs of the global community. In breakout groups on the final day, highlights for the future were discussed in the categories of "Global Perspectives," "E-Resources for the Future," "Keeping Programs Current and Compelling," and "Effective Outreach." One recurring topic was the question of how to effectively handle the exciting but relentless evolution of new topics such as biomaterials, green processing, nanotechnology, and soft materials within the academic structure and time constraints. Following are key questions that were addressed during the conference: Are our programs directed toward graduates headed for research careers, or industrial careers? Do we aim to develop science comprehension/literacy in the nontechnical population? Do we focus on preparing the "Renaissance engineer" (the Harvard view, impressively articulated by V. Narayanamurti of Harvard Univ., USA)? Should academic degree programs extend for enough years to accommodate the new topics? Should there be a new emphasis on "integrated science" curricula (as strongly advocated in the presentation by C.N.R. Rao of the Jawaharlal Nehru Centre for Advanced Scientific Research, India)? The opinions expressed by other participants on these and a variety of other key topics will be reviewed in a "Forum Report," to be published as part of the complete symposium proceedings in a special issue of the Journal of Materials Education.

Organization of the conference was made possible with generous sponsorship from NUS, IMRE, NTU, Singapore Agency for Science, Technology, and Research (A*STAR), Singapore Defence Science and Technology Agency (DSTA), and the French Embassy in Singapore.

B.V.R. CHOWDARI

Organizing Chair \& President of MRS-Singapore Department of Physics National University of Singapore

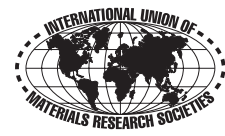

\section{MRS 2005 MRS Fall Meeting}

\section{research 08 tools -}

As a complement to the 2005 MRS Fall Meeting, the Materials Research Society is pleased to continue Research Tools Seminars, an exciting educational program that focuses on the scientific basis and practical application of commercially-available, stateof-the-art tools for materials research.

Held in the Exhibit Hall and free-of-charge to meeting attendees, these one-hour seminars describe a technical approach to meet a particular challenge, as embodied in commercially-available products or tools.

\section{TUESDAY, NOVEMBER 29}

3:30 pm- Efficient Fluorimetric Analysis of Single-Walled Carbon Nanotubes 4:30 pm APPLIED NANOFLUORESCENCE, LLC • BOOTH 824

4:30 pm- Molecular Recognition and Force Mapping with PicoTREC-A Novel AFM Technique 5:30 pm MOLECULAR IMAGING • BOOTH 902

\section{WEDNESDAY, NOVEMBER 30}

11:00 am- Combining AFM/SPM Systems with microRaman

12:00 pm NANONICS IMAGING LTD. • BOOTH 916

3:30 pm- New Optical, Non-Contact Instruments for Thermo-Mechanical Analysis

4:30 pm EXPERT SYSTEM SOLUTIONS S.R.L. • BOOTH 1212

4:30 pm- What is Quartz Crystal Microbalance/Heat Conduction Calorimetry?

5:30 pm MASSCAL CORPORATION • BOOTH 1106 


\section{E-MRS Spring Meeting Examined Broad Spectrum of Materials Science}

The 22nd European-Materials Research Society Spring Meeting, held at the Palais de la Musique et des Congrès in Strasbourg, France, May 31-June 3, 2005, offered a record 2850 presentations in 16 parallel technical symposia.* The meeting also featured five plenary talks, three satellite events, and graduate student awards in each technical symposium. In addition, the meeting hosted an industrial and commercial exhibition with well over 50 exhibitors, including for the first time a contribution from the Russian Federation.

Following the welcome address by EMRS President $\mathrm{H}$. Grimmeiss at the beginning of the Wednesday morning plenary session, Jacques Bouchard, special advisor to the chair and CEO of CEA Saclay, France, gave a presentation on "Preparing the Future: New Challenges for Nuclear Energy Systems." Population growth and development are expected to increase energy needs by $2-5$ times in the next 50 years, he said, and for sustainable development, nuclear energy will be a necessary part of the energy solution. Firstgeneration reactors (built from the 1950s to the 1970s) are nearing the end of their intended lives, so one aspect of nuclear development is the possible extension of the useful life of these reactors by countering degradation due to neutron irradiation, high temperature, mechanical stress, and corrosion. Reactors that were built more recently are safer than firstgeneration reactors by a factor of 10 , with a greatly reduced risk of meltdown. New reactors have improved containment and heat removal, higher plutonium consumption, and less waste generation, but that is not enough. Looking to the future, Generation IV reactors (to be built 20-30 years from now) aim to generate sustainable nuclear energy without the emission of greenhouse gases. An urgent need is to reduce nuclear waste- especially plutonium-due to public concern. A goal for Generation IV reactors is to discover systems to reduce the duration of radiotoxicity to a few hundred years, because it would be more straightforward to prepare reliable storage for hundreds of years rather than thousands of years, as is now the case. Reactors will need to burn fuel more completely and produce less waste, such as fast neutron reactors. Plutonium recycling can further reduce waste. Bouchard presented various reactor options, such as sodium-cooled and gascooled fast reactors. As to fusion reactors, *Symposium M on dendritic macromolecules
was canceled.

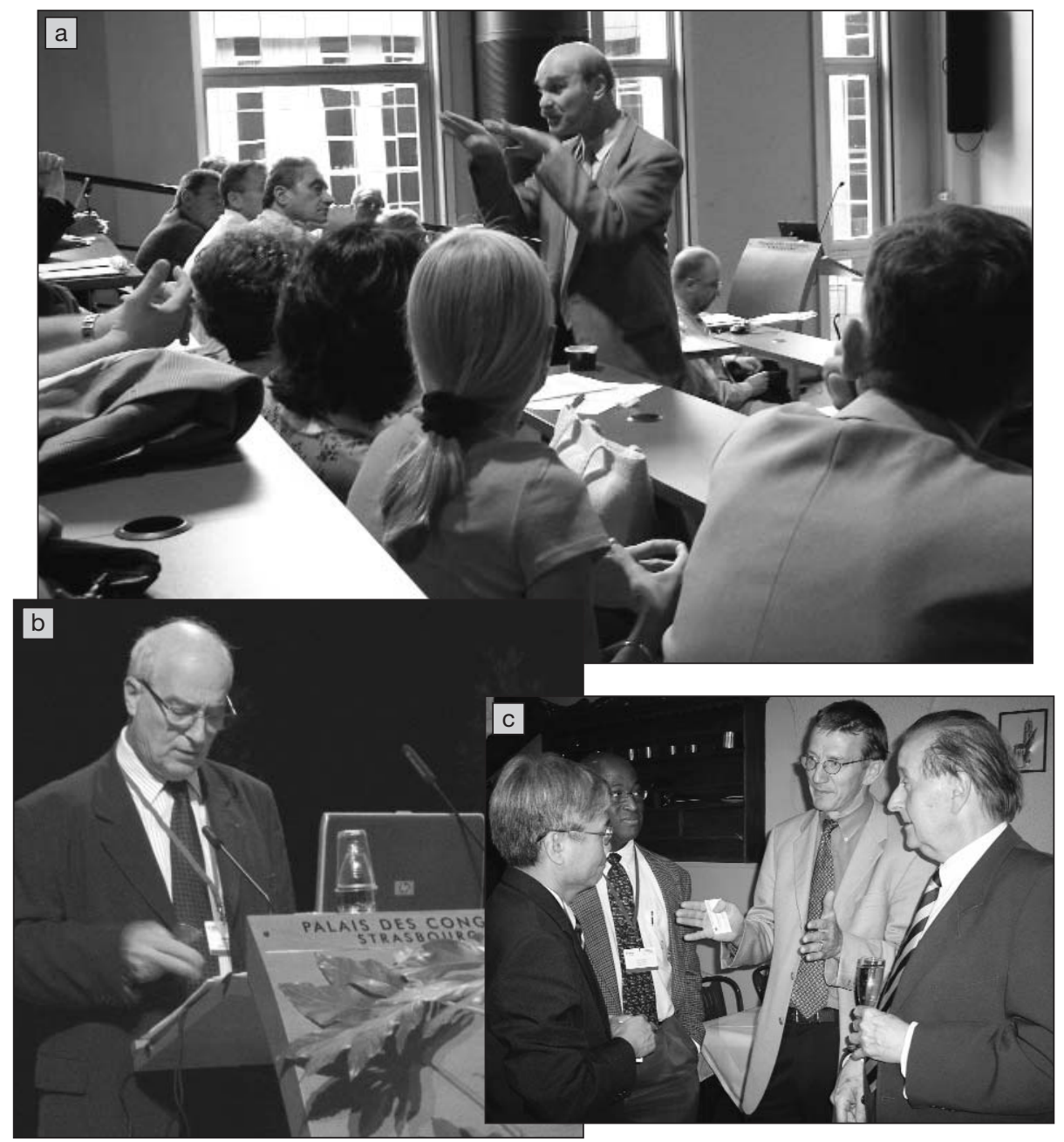

(a) Mark Ratner of Northwestern University at the Forum on Europe-USA Collaboration in Materials Research. (b) J. Bouchard (Nuclear Energy Director, CEA Saclay) speaking during the plenary session at the 2005 E-MRS Spring Meeting. (c) (Left to right): G.C. Chi, deputy minister, National Science Council, Taiwan; P. Green, MRS vice president; D. Eaglesham, MRS president; $P$. Siffert, E-MRS general secretary.

Bouchard envisioned that such reactors would be part of the solution 50-60 years hence, but cannot be put into the equation until its development trajectory settles.

Sune Svanberg (chair of the Nobel Committee for Physics; Lund Institute of Technology, Sweden), offered insights into the process of awarding Nobel Prizes in physics. The award is given for discovery or invention-rather than for lifetime achievement-and it is based purely on scientific excellence, without regard for diversity, geography, or gender. The prize-awarding institution is the Royal Swedish Academy of Sciences. The Nobel Committee invites nominations, due by February 1, from people in the field of physics, including the Royal Academy members, previous Nobel Laureates, Nordic physics professors, physics professors at selected universities (on a rotating basis), and persons at non-university research institutions. Experts assess prizeworthiness across all areas of physics, based on a yearly statement that reviews all fields of physics. Announcements are made in October, and the prize ceremony is December 10, the anniversary of Alfred Nobel's death. Information regarding nominations, investigations, and opinions concerning the Prizes, including the yearly assessment of the field, is kept secret for 50 years. See Web site www.nobel.se for more information, including a summary of the nomination and selection process for physics Laureates and award lectures. 


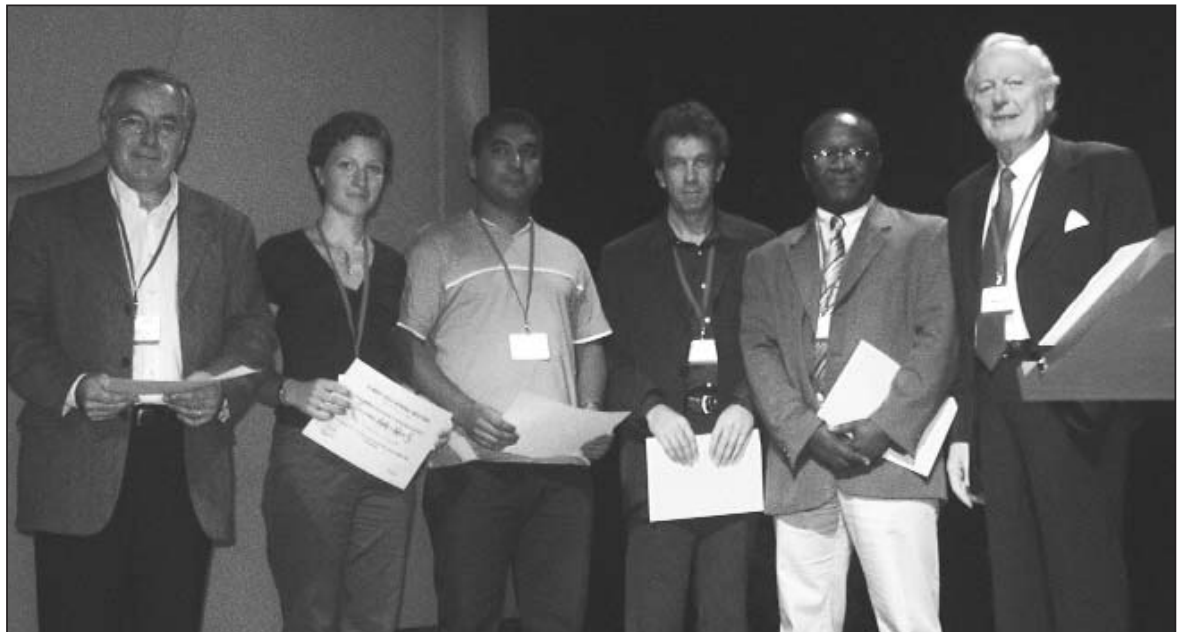

E-MRS President H. Grimmeiss of the University of Lund, Sweden, (right) presents the Symposium C Graduate Student Award.

"Prediction is hard. Especially if it's about the future," said Claus Weyrich (member of the Managing Board of Siemens AG, and head of corporate technology), quoting Niels Bohr. ${ }^{+}$But despite complexity and uncertainty, Weyrich said, having a plan is helpful. With that in mind, he speculated on the future of socioeconomic, market, customer/business, and technological trends, and how such forces might express themselves in technology sectors. Socioeconomic factors include a mobile workforce, a growing and aging population, increased environmental load, lifelong learning, globalization, and the need for filtering and structuring the growing amount of information. For example, in the area of information and communications, telephones, computers, and other technologies are merging and leading to human-computer cooperation rather than just interaction. The future could make use of the detection of speech, gestures, handwriting, and eventually facial expressions, emotions, and brain activity. Moving beyond information processing is content comprehension through concepts such as a semantic Web. From here one can "retropolate," going from the visionary future back to the present by strategic planning of innovation and technology. Weyrich also considered automation and control, transportation, and health. The solutions are interdisciplinary, he said, and will appear on the market when affordable, rather than when feasible. Important materials solutions can be expected in nanotechnology, functional materials, lightweight materials, biochips,

\footnotetext{
'The actual quote attributed to Niels Bohr uses "very difficult."
}

intelligent displays, and sensors. While it is hard to plan for the unknown, companies can develop agility by combining extrapolation and "retropolation" to better position themselves, Weyrich said.

G.C. Chi (Deputy Minister, National Science Council, Taiwan) gave an overview of Taiwan's national research and development program on white lightemitting diode (LED) lighting. Taiwan has been in the LED business for 40 years and is second in the world in the production of LEDs, behind Japan. Taiwan's investment in the past 10 years has been particularly heavy in blue LEDs. In his presentation, Chi reviewed the history of lighting and examined the structure and priorities of Taiwan's science and technology program from $R \& D$ to industrial developments and promotion. Taiwan's goal is to move from current lighting options to semiconducting light sources by 2020. Incorporation of LEDs is expected to move from information displays to auto optoelectronics, biomed-optoelectronics, and then to energy applications (home lighting). Challenges remain in the areas of cost, quality assurance in cars, energy savings in the lighting market, and solar cells.

The plenary session concluded with a summary by Aleksandar Jovanovic (MPA Stuttgart, Germany) concerning the status of EuMaT, the European Technology Platform on Advanced Engineering Materials and Technologies. The organization's aim is to define priorities, optimize R\&D investment, and assure synergy in advanced engineering materials. EuMaT has more than 350 members from industry, universities, professional associations, government, and other organizations. Deliverables include a two-page summary form, a vision paper with a 10-year horizon, a strategic research agenda, and an implementation agenda. See their Web site www.eumat.org for more information.

Satellite events held in conjunction with the conference were the National Science Foundation (USA)-Europe Grantees Meeting and Forum on European and USA collaboration in Materials Research, an E-MRS Short Course on Materials Surface Processing (MATSUP) devoted to "Deposition and Characterization of Surface Coatings and Thin Films," and an E-MRS Industrial Forum, "In Situ Diagnostic and Control Systems in Laser Materials Processing-Recent Developments for Industrial Applications."

The technical symposia were divided into four groups: Electronics and Photonics, Thin Film and Nanostructured Materials, Materials Synthesis and Fabrication, and Modeling and Characterization. Following are highlights of the research presented in the technical sessions.

In the areas of electronics and photonics, scientists presented their results in this fast-growing research area that includes the development and integration of new processes and new materials for the fabrication of future generations of integrated circuits. In the opening session of Symposium D, T. Skotnicki (STMicroelectronics, France) gave an overview of nonclassical complementary metal oxide semiconductor (CMOS) device structures [e.g., ultrathin single- and double-gate devices such as silicon-on-insulator (SOI)] and explained their fundamental role in assuring the successful persistence of device miniaturization trends following Moore's law. Two sessions in Symposium D on future silicon-based technologies were dedicated to new materials in the semiconductor industry to improve carrier mobility (e.g., strained $\mathrm{Si}$ and $\mathrm{SiGe}$ ) and limit parasitic effects (e.g., SOI). B. Ghyselen (SOITEC, France) showed how both materials types can be combined into a single process and proposed strained silicon-on-oxide as a better alternative to $\mathrm{SiGeOI}$ to achieve a successful structure. E. Fitzgerald (Massachusetts Institute of Technology, USA) reviewed several engineered channel structures enabling a simultaneous improvement of both electron and hole mobility, including strained Si, dualchannel strained Si-strained SiGe, trichannel strained $\mathrm{Si} / \mathrm{SiGe} / \mathrm{Si}$, and symmetric strained Si-strained Ge. Although a considerable gain is still expected for these structures, Fitzgerald proposed that a more substantial improvement would come from the integration of III-V channel devices onto engineered Si-based supports.

In the sessions of Symposium D devot- 


\section{Graduate Student Awards Presented at the 2005 E-MRS Spring Meeting}

Symposium A: Current Trends in Nanoscience-

\section{From Materials to Applications}

Maria Nichick (Belarusian State Univ., Minsk, Belarus): Optical and Electrophysical Properties of Ag PEPK Nanocomposites

Alina Veligura (Kiev National Taras Shevchenko Univ., Kiev, Ukraine): Comprehensive Review: Self-Organized Nanosystems on Biological Molecule/Metal Nanoparticle Building Blocks: Nanostructure, Bonds, Photosensitivity and Biomedical Applications

\section{Symposium B: Spintronics}

Mircea Vomir (Institut de Physique et Chimie des Matériaux de Strasbourg, Univ. Louis Pasteur, Strasbourg, France): ThreeDimensional Spin Dynamics Induced by Ultrashort Optical Pulses in Cobalt Thin Films

Loïc Joly (Institut de Physique et Chimie des Matériaux de Strasbourg, Univ. Louis Pasteur, Strasbourg, France): Spin Precession of Electrons Reflected from a Ferromagnetic Surface

\section{Symposium C: Rare-Earth-Doped Photonic Materials}

Nasser Afify (INFM and Department of Physics, Povo, Trento, Italy): Short-Range Order Around Er in Silica Waveguides Containing $\mathrm{Al}$, Ti, and $\mathrm{Hf}$

Géraldine Dantelle (Laboratoire de Chimie Appliquée de $\mathrm{l}^{\prime}$ Etat Solide, Paris, France): Influence of $\mathrm{Yb}^{3+}$ and $\mathrm{Ce}^{3+}$ Doping on the Structure and Luminescence of $\mathrm{Er}^{3+}$-Doped Transparent Glass-Ceramics

Symposium D: Materials Science and Device Issues for Future Si-Based Technologies

Andy Smith (Advanced Technology Institute, Univ. of Surrey, Guildford, UK): Suppression of Boron Interstitial Clusters in SOI Using Vacancy Engineering

Saurabh Gupta (Massachusetts Institute of Technology, USA): Improved Hole Mobilities and Thermal Stability in a Strained-Si/Strained-Si ${ }_{1-y} \mathrm{Ge}_{y} /$ Strained D-Si Heterostructure Grown on a Relaxed $\mathrm{Si}_{1-x} \mathrm{Ge}_{x}$ Buffer

Symposium E: Synthesis, Characterization, and Applications of Mesostructured Thin Layers

Sandrine Dourdain (Laboratoire de Physique de l'Etat Condensé, Univ. du Maine, Le Mans, France): Determination of Porous Properties of Mesoporous Silica Thin Films by Quantitative X-Ray Reflectivity Analysis and GISAXS

\section{Symposium F: Thin-Film and Nanostructured Materials} for Photovoltaics THINC-PV2

Franck Hergert (chair for Crystallography and Structural Physics, Univ. of Erlangen-Nürnberg, Erlangen, Germany): A Thermodynamical Approach to the Formation Reactions in Sodium-Doped Cu(In,Ga)Se 2

Axel Straub (Centre for Photovoltaic Engineering, Univ.of New South Wales, Sydney, Australia): Homoepitaxial Silicon Growth in a Non-Ultrahigh-Vacuum Environment by IonAssisted Deposition on Si Wafer and Seeded Glass Substrates

Zhibin Xie (Univ. of Oxford, UK): A Microstructural and Device Performance Study of Solar Cells with Differently Fabricated Titania Layers

\section{Symposium G: $\mathrm{ZnO}$ and Related Materials}

Filip Tuomisto (Laboratory of Physics, Helsinki Univ. of
Technology, Espoo, Finland): As-Doped p-Type ZnO Studied by Positron Annihilation Spectroscopy

Oliver Schmidt (Palo Alto Research Center, USA): Analysis of a Conducting Channel at the Native Zinc Oxide Surface

\section{Symposium H: Nanostructured and}

Intelligent Bioactive Materials

Valentina Carmen Dinca (NILPRP, Bucharest, Romania)

Sylvie Lousinian (Aristotle Univ. of Thessaloniki, Greece): Haemocompatibility of Amorphous Carbon Thin Films, Optical Properties and Adsorption Mechanisms of Blood Plasma Proteins

\section{Symposium I: Advanced Functional Nanomaterials- From Nanoscale Objects to Nanostructured Inorganic and Hybrid Materials}

Yuya Oaki (Faculty of Science and Technology, Keio Univ., Japan): Hierarchically Organized Architecture in Multiscales Emerging from Association of Crystals, Organic Polymers, and Dyes

Dario Buso (INSTM and Univ. di Padova, Italy): Nanoporous Sol-Gel Silica Film Doped with $\mathrm{NiO}$ and Au Nanocrystals for Optical and Electrical Gas Sensors

Symposium J: Advances in Laser and Lamp Processing of Functional Materials

EunSun Lee (Yonsei Univ., Seoul, Korea): Fabrication of the Hydrogen Resistive Ferroelectric Film of the $\left(\mathrm{Pb}_{0.72} \mathrm{La}_{0.28}\right) \mathrm{Ti}_{0.93} \mathrm{O}_{3} /$ $\mathrm{Pb}\left(\mathrm{Zr}_{0.53} \mathrm{Ti}_{0.47}\right) \mathrm{O}_{3} /\left(\mathrm{Pb}_{0.72} \mathrm{La}_{0.28}\right) \mathrm{Ti}_{0.93} \mathrm{O}_{3}$ Heterostructure by a Pulsed Laser Deposition Method

Irving Ian Liaw (Univ. College London, UK): Stable Tantalum Pentoxide Thin Films Grown on Si Surfaces Nitrided at Room Temperature in Nitrogen-Containing Ambients by Excimer Photons

Symposium K: Protective Coatings and Thin Films-05

Alireza Akbari (Laboratoire de Métallurgie Physique, Univ. de Poitiers, Chasseneuil Futuroscope, France): Structural and Mechanical Properties of IBAD-Deposited Nanocomposite $\mathrm{Ti}_{1-x} \mathrm{Ni}_{x} \mathrm{~N}_{y}$ Coatings

Angélique Bousquet (LPCM-IMN, Univ. de Nantes, France): Comparison of Structure and Mechanical Properties of $\mathrm{SiO}_{2}$-Like Films Deposited in $\mathrm{O}_{2} /$ HMDSO Pulsed and Continuous Plasmas

Symposium L: Materials for Hydrogen and

Fuel Cell Technologies

Barbara Panella (Max-Planck-Institut für Metallforschung, Stuttgart, Germany): Physisorption of Hydrogen in Microporous Materials

\section{Symposium N: Nuclear Materials}

Jean-Nicolas Cachia (Commissariat à l'Energie Atomique, DEN/DTCD/SECM/LMPA, Bagnols-sur-Cèze Cedex, France): Solubility Improvement of Cerium and Plutonium by Reduction in Borosilicate Glasses

Christoph Pistner (Interdisciplinary Research Group Science, Technology and Security, Darmstadt Univ. of Technology, Darmstadt, Germany): Neutronics Calculations on the Impact of Burnable Poisons to Safety and Non-Proliferation Aspects of Inert Matrix Fuels 
Symposium O: Synchrotron Radiation and Materials Science

Z. Budrovic (Paul Scherrer Institute, Switzerland): Footprints of Deformation Mechanism during In Situ X-Ray Diffraction Nanocrystalline and Ultra-Fine Grained Metals

Andersan Dos Santos Paula (CENIMAT, Monte de Caparica, Portugal): Study of the Textural Evolution in Ti-Rich NiTi Using Synchrotron Radiation

Symposium P: Current Trends in Optical and X-Ray Metrology of Advanced Materials for Nanoscale Devices

Luisa Raimondo (INFM and Dipartimento di Scienza dei Materiali, Univ. di Milano Bicocca, Italy): Absorbance Spectra of Polycrystalline and Samples and Twinned Crystals of Oligothiophenes

Tong Da Ma (General Research Institute for Nonferrous Metals, Beijing, China): X-Ray Triple-Axis Diffractometry
Investigation of $\mathrm{Si} / \mathrm{SiGe} / \mathrm{Si}$ on Silicon-on-Insulator Subjected to In Situ Low-Temperature Annealing

Symposium Q: Materials Science and Cultural Heritage

Brooke Rosenzweig (Univ. of Florence, Sesto Fiorentino, Italy): Use of Mid-Infrared Fiber-Optic Reflectance Spectroscopy to Determine Efficacy of Micro-Emulsion Cleaning Agents in Fresco Conservation

Gümsu Simsek (Istanbul Technical Univ., Istanbul, Turkey): Characterization of Silver and Gold GILT Silver Wires from Five "KISWA," Embroidered Silk Kaaba Covers Presently Exhibited at the Topkapi Palace Museum, Dated Between 16th and 19th Centuries

Eleonore Welcomme (Centre de Recherche et de Restauration des Musées de France): Investigation on White Pigments Used as Makeup During the Greco-Roman Period ed to dopant characterization techniques, P. Eyben (IMEC, Belgium) reviewed recent progress in scanning spreading resistance microscopy capabilities, highlighting simultaneous performances in terms of sensitivity $(<10 \%)$, spatial resolution (1-3 nm), dopant gradient resolution (1-2 nm/decade), and quantification accuracy. F. Giannazzo (IMM-CNR, Italy) reported on recent results obtained using scanning tunneling microscopy. In particular, he demonstrated that a spatial resolution of $1 \mathrm{~nm}$ can be achieved with this technique and gave several examples of applications in deep-submicrometer technologies, including the study of B diffusion and electrical activation, the influence of point defects on dopant distribution, and size effects in nanostructures.

Dopant diffusion and activation anomalies in both $\mathrm{Si}$ - and SiGe-based materials, including the role of strain, point defects, and impurities, were discussed during several sessions in this symposium in which both experimental and simulation studies were reported. V.C. Venezia (Axcelis, USA) presented a detailed study of boron diffusion in amorphous silicon, providing insight into junction formation in pre-amorphized silicon. L.A. Marques (Univ. of Valladolid, Spain) reviewed current models used in process simulation tools and underlined the need to shift from continuum models to atomistic ones since devices are shrinking to the nanometer scale. In particular, he showed how a hierarchical simulation scheme from fundamental techniques to extract parameters (e.g., ab initio, tight binding, and classical molecular dynamics), to simulations that allow direct comparison with experiments (such as Monte Carlo), bridges the gap between atoms and experiments. I. Bork (Synopsys, USA) gave an extensive overview of current trends, demands, and challenges in
TurboCAD, with a particular emphasis on the peculiar use of TCAD in a "fab environment." To illustrate this point, he discussed the case of layout-dependent device, where the use of TCAD represents the cheapest solution to define successful integrated circuit design.

Other highlights in the area of electronics and photonics featured current trends in nanoscience (e.g., spin memory devices, controlled growth on magnetic nanoclusters and biomedical applications, hybrid materials and systems, and soft/hard as well as organic/inorganic and biological synthetic surface interfaces) and rare-earthdoped photonic materials. Among the highlights of the latter area were discussions of the development of new phosphors for mercury-free fluorescent lights and novel methods for the efficient sensitization of rare-earth ions in gallium nitride. In addition, attention was given to the suppression of multiphoton processes in rareearth-doped glass ceramics and doped MOS devices producing emission across the visible and ultraviolet wavelengths.

The topic of thin films and nanostructured materials included a symposium on nanostructured and intelligent bioactive materials in which S. Lecommandoux (Univ. of Bordeaux, France) reported on $\mathrm{pH}$-responsive vesicles based on polypeptide diblock copolymers. The resulting structures showed a stimuli-sensitive behavior to $\mathrm{pH}$ and ionic strength that can be utilized to control size and shape. Micelle-based nanoparticles were also presented for which the $\mathrm{pH}$ sensitivity can be used for controlled release of encapsulated drugs. T. Berlind (Linköping Univ., Sweden) reported on biosorption studies of carbon nitride films using in situ ellipsometry, human serum albumin adsorption proved to be stronger on the amorphous films than on the ordered case. In another presentation, with a combination of hy- droxyapatite and a self-assembled peptide, E. Garreta (Massachusetts Institute of Technology, USA) fabricated a threedimensional nanostructured biomaterial for tissue engineering of bone. While the peptide forms a three-dimensional network of nanofibers, the surface-modified hydroxyapatite provides the necessary stability.

In the area of oral and maxillofacial surgery, D. Muster (CHRU, France) showed the shortfalls of current metalbased implant solutions to fix complicated defects, including the inability of these materials to follow age-related growth processes. There are new attempts to apply biodegradable polymer-based implant solutions instead. However, because of their weaker mechanical performance, these polymer implants are typically larger than their metal analogues, which can lead to problems in practical applications. P.J. Lutz (CNRS, France) reported on the advantages of using poly(ethylene oxide) hydrogels as scaffold materials, including their well-controlled porosity, high level of biocompatibility, and almost zero nonspecific protein adsorption, which leads to a non-thrombogenic material. H. Arwin (Linköping Univ., Sweden) reported on research that focuses on the temperature stability of multilayers of anti-human serum albumin and its antigen, since biomimetic materials are currently more often used at elevated temperatures. Infrared ellipsometry studies of temperature effects on the multilayers showed that the films were stable up to about $120^{\circ} \mathrm{C}$ while at $200^{\circ} \mathrm{C}$, considerable decay could be detected.

Highlights from the symposium on Synthesis, Characterization, and Applications of Mesostructured Thin Layers included research results on ordered mesoporous layers on mixed oxide layers, nanocomposite and hybrid layers, double 


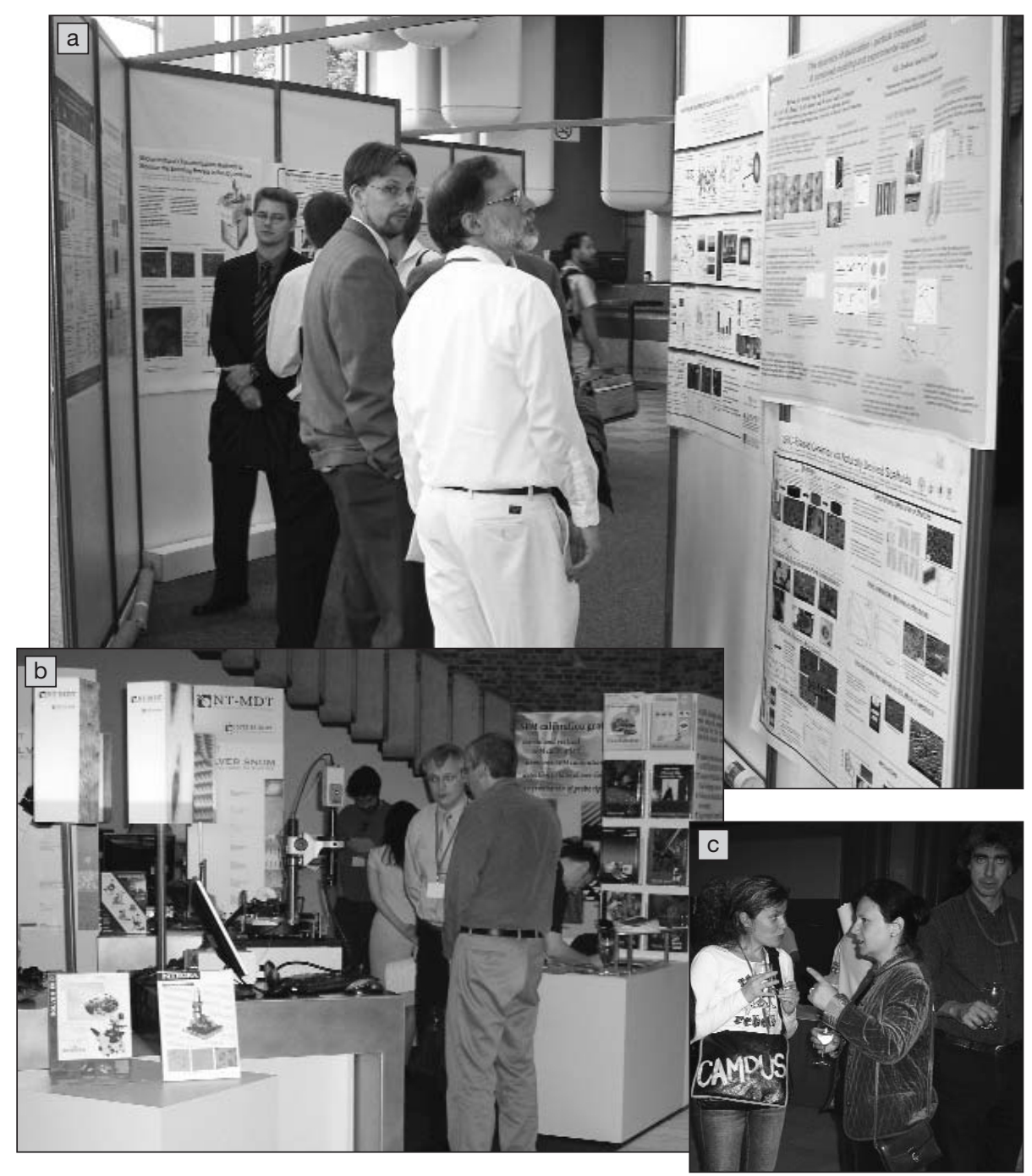

(a) Poster session and (b) equipment exhibition at the 2005 E-MRS Spring Meeting. (c) Meeting attendees converse with their colleagues.

hydroxide-based layers, and functionalized and biometric films. The scientific challenge of thin-film characterization was met with techniques such as ellipsometry, $\mathrm{x}$-ray reflectivity, and scattering analysis.

While no breakthrough in hydrogen storage was reported in the symposium on Materials Synthesis and Fabrication, complex hydrides received much attention in the symposium on materials for hydrogen and fuel cell technologies. With reversibility of storage as a key topic, the role of catalysts was clearly demonstrated, even though it is not yet well understood. The role and characterization of various nano-sized particles of different origin were an issue in many presentations: $d$-metal particles were added on purpose (e.g., catalysis) or formed upon hydrogen sorption cycles in the bulk or near-surface region by phase separation or disproportionation reactions. They were characterized by means of tunneling electron microscopy, extended $x$-ray absorption fine structure, and x-ray diffraction. As the more electropositive hydride-forming component might be etched away easily, these hydrogenation reactions offered a new way for synthesizing metallic nanoparticles.

The symposium on nuclear materials included the 10th Inert Matrix Fuel Workshop, which was concerned with the behavior of inert matrix fuel in light-water reactors and in advanced systems such as a deep-burner gas-cooled reactor or an accelerator-driven system. New production routes for silicon carbide and beryllium oxide were described. Zirconia remains one of the most successful inert matrix materials; it may, however, be embedded in a heat-conducting material when used in a power reactor. The symposium included sessions on nuclear fuels for thermal and advanced nuclear reactors and waste forms, focusing on production, performance, and nonproliferation issues, and on specific work with regard to the geological disposal of actinide oxides, titanates, and phosphides.

One of the main focal points of Symposium $\mathrm{P}$ within the group of symposia on modeling and characterization was the ellipsometric and optical polarization characterization of thin films and nanostructured materials. Although ellipsometry measurements of isotropic materials have been standard for some time, ellipsometry of anisotropic materials is becoming much more important. R.W. Collins (Univ. of Toledo, USA) and M. Schubert (Univ. Leipzig, Germany) discussed both the instrumentation and the interpretation of generalized ellipsometry where sample isotropy is not assumed. Collins showed that timeresolved complete Mueller matrix ellipsometry can be performed with his dual rotating compensator instrument, and Schubert discussed his recent work on ellipsometry of anisotropic materials, particularly in the infrared region.

Normal incidence optical anisotropy has been used for years to characterize thinfilm growth of III-V semiconductors using reflection difference spectroscopy (RDS). This is now a commercially available technique from LayTec GmbH (Germany) and was summarized by T. Zettler. Another major advance in ellipsometric capability is the extension of measurements into the vacuum ultraviolet (VUV) region. This is particularly important for photolithography, where ultraviolet light from ArF excimer lasers $(193 \mathrm{~nm})$ are used for feature definition in many semiconductor device technologies. The application of this new technology was summarized by N.V. Edwards (SEMATECH, USA), who discussed the use of VUV ellipsometry to determine the optical properties of silicon and thin-film high- $\kappa$ dielectric materials.

Another main focus of the symposium was the $x$-ray characterization of thinlayered materials. X-ray reflectometry provides the electron density profile, as described by A. Gibaud (Univ. du Maine, France) in relation to the study of mesoporous silica thin films. Besides the descriptions of some innovative methodological approaches in x-ray scattering given in this session, a strong trend concerning spatially resolved studies of small objects, using synchrotron radiation, has been brought to the fore by many invited 
speakers. V. Holý (Charles Univ. Prague, Czech Republic) described structural characterizations of self-organized semiconductor quantum dots and wires by using anomalous scattering with energy close to an absorption edge of constituent atoms, thereby enhancing the sensitivity of the $x$ ray scattering and enabling the study of very small volumes of scattering objects. The synchrotron-radiation diffractionrocking-curve imaging technique was described by P. Mikulík (Masaryk Univ., Czech Republic) as a powerful method to study the local lattice and structure control of semiconductor wafers and surface structures with spatial resolution down to $1 \mu \mathrm{m}$ over an extended sample area. In addition, a review of some recent and promising results in the field of strain measurements in small dimensions by $x-$ ray diffraction experiments from third generation synchrotron radiation sources was given by O. Thomas (Univ. Paul Cèzanne, France).

Presentations were given on highdielectric-constant films, since these films have the potential to replace $\mathrm{SiO}_{2}$ as the gate dielectric in CMOS devices. Spectroscopic ellipsometry was often the primary diagnostic technique applied, but several researchers apply other techniques such as high-resolution transmission electron microscopy, x-ray reflectometry, infrared transmission, and Raman scattering. The combination of techniques is particularly important for ellipsometric measurements, since spectroscopic ellipsometry is indirect. The electronic structure of many high- $\kappa$ dielectric films near the band edge was discussed by G. Lucovsky (North Carolina State Univ., USA), who applied x-ray absorption, photoconductivity, and VUV spectroscopic ellipsometry to study these materials. Moreover, A. Boulle (CNRS UMR, France) reported an extensive study of defects in oxide thin layers by reciprocal space mapping experiments using highresolution x-ray diffractometry. Regarding nitride-based materials, L. Kirste (Fraunhofer-Institut für Angewandte Festkörperphysik, Germany) presented a study of (Al,Ga)N/GaN-based heterostructures for high-electron-mobility transistor structures using $\mathrm{x}$-ray topography in transmission geometry with a resolution of a few tens of micrometers.

Symposium P closed with a round-table discussion on ellipsometric characterization of films that are not uniform, where the refractive index changes with depth into the film, and films that are very thin. The complementary aspects of optical and x-ray scattering metrologies was also addressed. A topic recommended for future consideration was optical characterization of two- and three-dimensional photonic crystal materials, which may require polarization-dependent optical characterization.

The application of synchrotron $x$-ray techniques to particular materials science problems was addressed in Symposium O and included sessions devoted to nanostructures, semiconductors, and optical materials; mesoporous materials; surfaces and interfaces; and complex and biomaterials. Two joint sessions were organized with symposia on cultural heritage (Q) and spintronics (B) as well. The invited presentations in Symposium O highlighted how the availability of high-brilliance synchrotron $x$-ray beams allows great advances to be made in the understanding of materials properties.

Plans are underway for the 2006 EMRS Spring Meeting, which will be held in combination with the International Union of Materials Research Societies International Conference on Electronic Materials. The meeting will be held in Nice for the first time, at the Acropolis Congress Center, on May 29-June 2, 2006, and will consist of 23 technical symposia, including one on materials education.

JOHN BLIZZARD

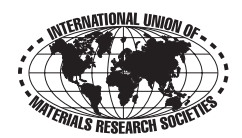

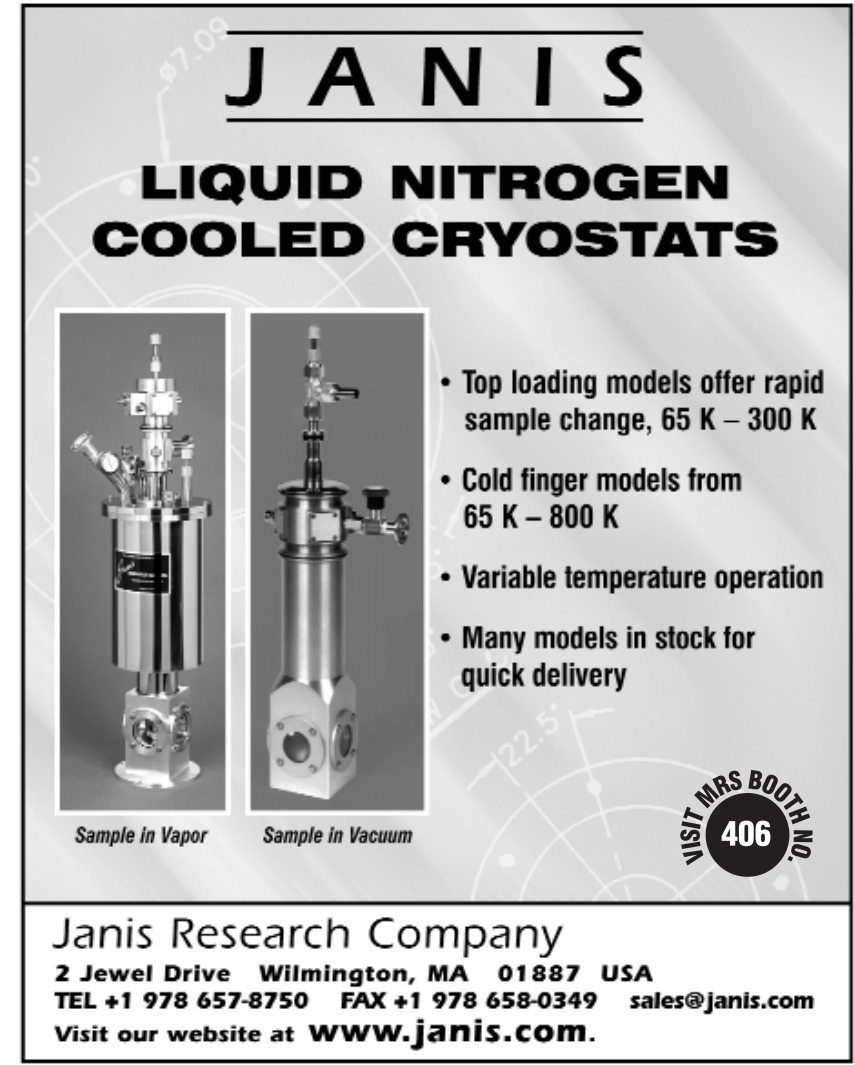

For more information, see http://advertisers.mrs.org

\section{Nanopositioning Systems}

Closed Loop, Sub-Nanometer Precision for
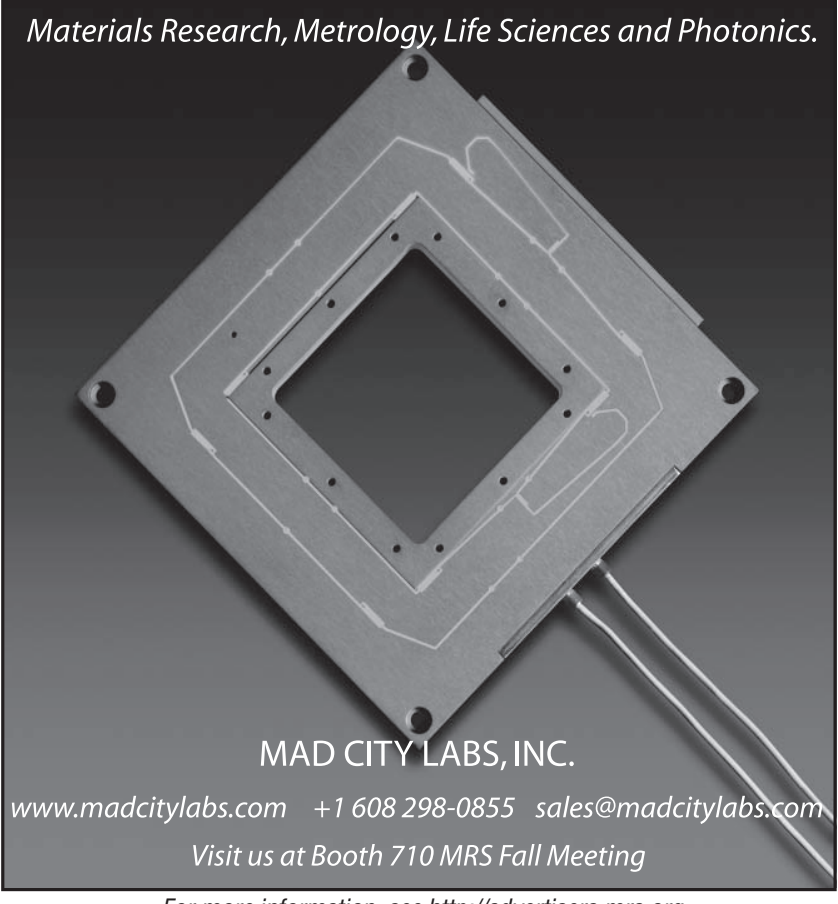

For more information, see http://advertisers.mrs.org 